九州大学学術情報リポジトリ

Kyushu University Institutional Repository

\title{
Rapid Synthesis of W_180_49 via Reactive Spark Plasma Sintering with Controlled Anisotropic Thermoelectric Properties
}

\section{Nhat Quang Minh Tran}

Department of Applied Science for Electronics and Materials, Interdisciplinary Graduate School of Engineering Sciences, Kyushu University

Ohtaki, Michitaka

Department of Applied Science for Electronics and Materials, Interdisciplinary Graduate School of Engineering Sciences, Kyushu University

Suekuni, Koichiro

Department of Applied Science for Electronics and Materials, Interdisciplinary Graduate School of Engineering Sciences, Kyushu University

https://doi.org/10.5109/4480715

出版情報: Evergreen. 8 (2)，pp.344-350，2021-06. Transdisciplinary Research and Education Center for Green Technologies, Kyushu University

バージョン :

権利関係： 


\title{
Rapid Synthesis of $\mathrm{W}_{18} \mathrm{O}_{49}$ via Reactive Spark Plasma Sintering with Controlled Anisotropic Thermoelectric Properties
}

\author{
Nhat Quang Minh Tran ${ }^{1}$, Michitaka Ohtaki ${ }^{1,2, *}$, and Koichiro Suekuni ${ }^{1,2}$ \\ ${ }^{1}$ Department of Applied Science for Electronics and Materials, \\ Interdisciplinary Graduate School of Engineering Sciences, Kyushu University, Japan \\ ${ }^{2}$ Transdisciplinary Research and Education Center for Green Technologies, Kyushu University, Japan
}

*Corresponding Author : E-mail: ohtaki@kyudai.jp

(Received January 29, 2021; Revised May 3, 2021; accepted May 16, 2021).

\begin{abstract}
Single phase $\mathrm{W}_{18} \mathrm{O}_{49}$ sintered polycrystalline samples were successfully synthesized via one-step rapid reactive spark plasma sintering directly from commercially purchased $\mathrm{WO}_{3}$ and $\mathrm{WO}_{2}$ powders. Thermoelectric properties of the samples sintered at 15 and $30 \mathrm{MPa}$ showed insignificant anisotropy, while a strong anisotropy was observed for the sample sintered at $50 \mathrm{MPa}$. The in-situ reaction under a high applied pressure allowed a preferential grain growth along the direction perpendicular to the pressure axis. The high anisotropy of the sample sintered at $50 \mathrm{MPa}$ yielded the lowest thermal conductivity of $4 \mathrm{Wm}^{-1} \mathrm{~K}^{-1}$, resulting in a $Z T$ value of 0.08 at $1073 \mathrm{~K}$. This study offers the rapid and cost-effective preparation method for $\mathrm{W}_{18} \mathrm{O}_{49}$ materials, which can also be applied for other tungsten suboxide phases, with partially controlled anisotropic properties by the influence of applied pressure for thermoelectric performance enhancement.
\end{abstract}

Keywords: oxide thermoelectrics, lattice thermal conductivity, reactive spark plasma sintering, pressure-induced anisotropy, transition metal oxides

\section{Introduction}

Global warming, fossil fuel depletion, and excessive $\mathrm{CO}_{2}$ emission have urged the development of green alternative power sources such as wind, solar, geothermal energy, etc ${ }^{1-4)}$. Another direction to tackle the energy crisis is improving the efficiency of power usage through waste-heat recovery. Thermoelectricity is a potential candidate for direct waste-heat harvesting, with the conversion efficiency mainly dependent on its constituting materials through a dimensionless figure-ofmeritZT $=S^{2} T \rho^{-1} \kappa_{\text {tot }}^{-1}(S$, Seebeck coefficient; $\rho$, electrical resistivity; $\kappa_{\text {tot }}$, total thermal conductivity; $T$, absolute temperature). For practical applications, high $Z T$ thermoelectric materials are required to be developed from cost-effective and environmental-friendly elements.

Tungsten suboxide $\mathrm{W}_{18} \mathrm{O}_{49}$ has attracted much interests for its pseudo-one-dimensional porous crystal structure and high electrical conductivity, and can be isolated as a stable single phase ${ }^{5-9)}$. The crystal structure of $\mathrm{W}_{18} \mathrm{O}_{49}$ (Fig. 1 (a)) comprises corner-shared $\mathrm{WO}_{6}$ octahedra with pseudo-hexagonal void tunnels running along the crystallographic $b$-axis (Fig 1. (b)) sandwiched by large penta-columns (made of five $\mathrm{WO}_{6}$ octahedra, each sharing one edge with a $\mathrm{WO}_{7}$ bipyramid) ${ }^{10}$ ). The naturally ordered empty tunnels could act as phonon scattering centers with similar mechanism to the nanovoid embedded materials without seriously affecting the electrical properties ${ }^{11-13)}$. In addition, its bulky crystallographic unit cell containing a large number of atoms also contributes to the reduction of the lattice thermal conductivity $\kappa_{\text {lat }}$ due to the low group velocity of optical phonon modes ${ }^{14-16)}$. Overall, despite its metallic behavior, which is tunable by manipulating the carrier concentration ${ }^{17}$ ), $\mathrm{W}_{18} \mathrm{O}_{49}$ could be a promising new type of thermoelectric materials. Conventionally, $\mathrm{W}_{18} \mathrm{O}_{49}$ could be synthesized through solid-state processes with long reaction time. Consolidated samples for thermoelectric applications require additional densification steps via sintering at high temperature, however, with probability of decomposition into other sub-oxide phases. Moreover, it is difficult to obtain precise phase composition of $\mathrm{W}_{18} \mathrm{O}_{49}$ because there is high possibility of forming further reduced oxide phases due to the slow heating and cooling rates. A rapid synthesis process with direct consolidation could overcome those difficulties and provide better quality samples. Hence, fast and simple synthesis technique for $\mathrm{W}_{18} \mathrm{O}_{49}$ synthesis is highly desired.

Spark plasma sintering (SPS) has become one of the critical techniques for the past decades to synthesize modern advanced materials ${ }^{18)}$. An ability to attain very high heating rates with a simultaneously applied uniaxial pressure allows SPS to perform rapid densification (less than 1 hour) at lower sintering temperatures (hundreds of degrees lower) compared to conventional hot- 
pressing ${ }^{19,20)}$. Particularly, the rapid densification enables the minimized grain growth, which is highly desired for thermoelectric materials to preserve the enhanced grain boundary phonon scattering effects ${ }^{20-22)}$. Furthermore, under the influence of uniaxial pressure, preferential grain orientation is likely to occur, which could yield extraordinary results for materials with highly anisotropic crystal structures ${ }^{23,24)}$

It has been reported that the dc pulse current during SPS is highly suitable for initiating and facilitating the reactions of precursors, yielding nanograined product ${ }^{25)}$. This so-called reactive SPS can also synthesize materials within much shorter reaction time compared to conventional methods ${ }^{25-27)}$. Thus, here we report onestep direct synthesis and simultaneous consolidation of $\mathrm{W}_{18} \mathrm{O}_{49}$ from commercially purchased precursors via reactive SPS. The precursors were chosen to be $\mathrm{WO}_{3}$ and $\mathrm{WO}_{2}$ powders for the similarities in their crystals building blocks. Crystal structures of most of tungsten oxide and suboxide $\mathrm{WO}_{3-x}$ can be described by the different stacking orders of the $\mathrm{WO}_{6}$ octahedra. As shown in Figs. 1 (c) and (d), the $\mathrm{WO}_{2}$ crystal is formed by loosely connecting octahedra with some octahedra sharing edges together, while the $\mathrm{WO}_{3}$ crystal is made of ordered octahedra sharing the corners. Theoretically, this similarity could allow a straightforward in-situ reaction during SPS to form $\mathrm{W}_{18} \mathrm{O}_{49}$. Moreover, the highly anisotropic nature of $\mathrm{W}_{18} \mathrm{O}_{49}$ is expected to be preserved and enhanced during rapid reactive SPS, yielding anisotropic thermoelectric properties.

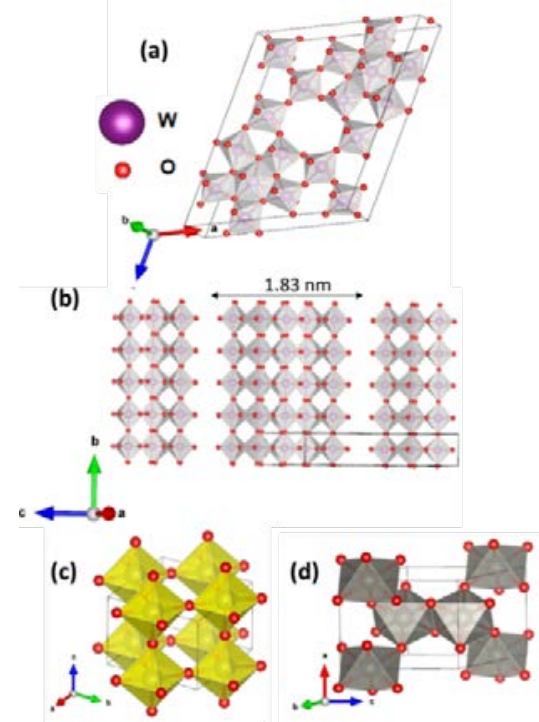

Figure 1. Crystal structure of $\mathrm{W}_{18} \mathrm{O}_{49}$ (a), view along [010] and [001] with intergrowth structure showing void tunnels running along [010] directions (b), of $\mathrm{WO}_{3}$ (c), of $\mathrm{WO}_{2}$ (d).

\section{Experimental details}

Commercially available materials $\mathrm{WO}_{3}$ (Kishida Chemical, 99.9\%) and $\mathrm{WO}_{2}$ (Wako, 99.9\%) were weighed according to the reaction $13 \mathrm{WO}_{3}+5 \mathrm{WO}_{2}=\mathrm{W}_{18} \mathrm{O}_{49}$, and well mixed in an agate mortar. Following the synthesis process in Fig. 2, the mixture was loaded into graphite dies of $10 \mathrm{~mm}$ in diameter and $60 \mathrm{~mm}$ in height, lined with carbon paper. The die was placed in the SPS furnace PLASMAN CSP-I-03121 (S. S. Alloy), and the furnace chamber was evacuated to $\leq 10 \mathrm{~Pa}$. Different die pressures ( $P=15,30$ and $50 \mathrm{MPa}$ ) were applied for the study on anisotropic thermoelectric properties. For the reactive SPS, the sample was heated up to $1423 \mathrm{~K}$ at a heating rate of $100 \mathrm{~K} \mathrm{~min}{ }^{-1}$ under respective uniaxial pressure, maintained at $1423 \mathrm{~K}$ for $15 \mathrm{~min}$, and the pressure was then released, and the cooling rate was controlled at $20 \mathrm{~K}$ $\mathrm{min}^{-1}$ to room temperature. The pellet was removed from the graphite die, and its surface was polished with $\mathrm{SiC}$ abrasive papers to remove all possible carbon contamination.

For characterization, bar-shaped and disc-shaped samples were cut along the direction parallel (//) and perpendicular $(\perp)$ to the applied pressure axis $P$ (Fig. 2). X-ray diffraction (XRD) data were collected using a Rigaku MiniFlex 600 diffractometer with $\mathrm{Cu} \mathrm{K} \alpha$ radiation, within the range of $6^{\circ} \leq 2 \theta \leq 50^{\circ}, \Delta 2 \theta=0.01^{\circ}$. Disc shaped samples were used for XRD, with observed planes parallel ( $P / /$ plane) and perpendicular ( $P \perp$ plane) to $P$, respectively. Surface morphologies were studied on a JEOL JCM-6000 Plus NeoScope scanning electron microscope (SEM) equipped with an energy-dispersive spectroscope (EDS). The electrical resistivity $\rho$ and the Seebeck coefficient $S$ were simultaneously measured under $\mathrm{Ar}$ atmosphere by dc four-probe method and temperature differential method, respectively, on an Ozawa Science RZ2001i apparatus. The thermal diffusivity $\alpha$ and the specific heat $C_{\mathrm{p}}$ at $300 \mathrm{~K}-1073 \mathrm{~K}$ were measured simultaneously on a Kyoto electronics LFA-502 by laser-flash method under vacuum. The absolute values of $C_{p}$ were derived from a comparative method between the measured values and standard $C_{\mathrm{p}}$ values of the molybdenum reference. The $C_{\mathrm{p}}$ values of all samples, measured from $300 \mathrm{~K}-1073 \mathrm{~K}$ was $0.31-0.40$ $\mathrm{J} \mathrm{g}^{-1} \mathrm{~K}^{-1}$, being equivalent to $1269-1639 \mathrm{~J} \mathrm{~mol}^{-1} \mathrm{~K}^{-1}$, reasonably agreed with the specific heat of $1668 \mathrm{~J} \mathrm{~mol}^{-1}$ $\mathrm{K}^{-1}$ calculated by the Dulong-Petit law. The thermal conductivity was calculated using the relation $\kappa=\alpha C_{\mathrm{p}} d_{\mathrm{s}}$, where $d_{\mathrm{s}}$ is the sample density. The measurements were performed for bar and disc samples according to their orientations with respect to the applied pressure axis. The reproducibility of the measured data was confirmed by cycled measurements on heating and cooling between 300 $\mathrm{K}-1073 \mathrm{~K}$.



Figure 2. Schematic of synthesis procedure and preparation 
process for TE characterizations of $\mathrm{W}_{18} \mathrm{O}_{49}$ by direct reactive $\mathrm{SPS}$ from $\mathrm{WO}_{3}$ and $\mathrm{WO}_{2}$ as starting materials.

\section{Results and discussion}

Sample sintered at $15 \mathrm{MPa}$ applied pressure showed 96\% relative density, while the others showed the relative density of approximately $100 \%$ of the theoretical density of $\mathrm{W}_{18} \mathrm{O}_{49}$. XRD patterns for the synthesized $\mathrm{W}_{18} \mathrm{O}_{49}$ samples are shown in Fig. 3 (a). The data were acquired from the $P / /$ and $P \perp$ planes. All the samples showed peak positions well agreeing with the simulated pattern of $\mathrm{W}_{18} \mathrm{O}_{49}$ crystal. It suggested that single phase $\mathrm{W}_{18} \mathrm{O}_{49}$ can be straightforwardly synthesized by reaction of $\mathrm{WO}_{3}$ and $\mathrm{WO}_{2}$ during the reactive SPS. This is remarkable, since other reports regarding the synthesis of monolithic ceramic $\mathrm{W}_{18} \mathrm{O}_{49}$ would involve multiple complicated steps $9,28,29)$.

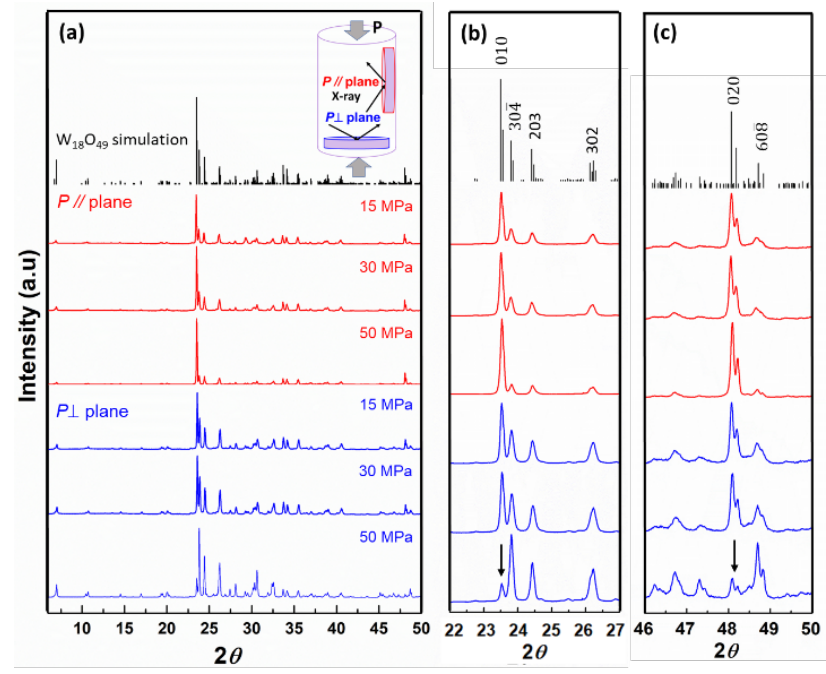

Figure 3. X-ray diffraction patterns for planes of SPS sintered $\mathrm{W}_{18} \mathrm{O}_{49}$ samples with different applied pressure 15, 30 and $50 \mathrm{MPa}$. The planes are parallel $(/ /)$ and perpendicular $(\perp)$ to the applied pressure axis $P$ during SPS (a), expanded $2 \theta$ scale from $22^{\circ}$ to $27^{\circ}$ (b), and from $46^{\circ}$ to $50^{\circ}$ (c). The arrows denote the suppression of (010) and (020) peaks.

In order to elucidate the anisotropic orientations, XRD patterns are shown in expanded $2 \theta$ sections, from $22^{\circ}$ to $27^{\circ}$ (Fig. 3 (b)), and $46^{\circ}$ to $50^{\circ}$ (Fig. 3 (c)). The arrows in the figures annotated the peaks with suppressed intensity, corresponding to the less favored directions of the crystal. Samples sintered under applied pressure of $15 \mathrm{MPa}$ and $30 \mathrm{MPa}$ showed insignificant anisotropy. However, the sample sintered under $50 \mathrm{MPa}$ showed very strong anisotropic patterns, similar to those reported patterns of $\mathrm{W}_{18} \mathrm{O}_{49} 1 \mathrm{D}$ structures ${ }^{5,30)}$. A remarkable enhancement of the (010) peak was observed for the $P / /$ plane, while both (010) and (020) peaks were strongly suppressed for the $P \perp$ plane. As shown in Table 1, the relative peak intensity of (010)/(30 $\overline{4})$ was enhanced from 3.47 to 8.69 for the $P / /$ plane, while for the $P \perp$ plane the $(010) /(30 \overline{4})$ ratio was suppressed from 1.54 to 0.28 as the SPS pressure increased from $30 \mathrm{MPa}$ to $50 \mathrm{MPa}$. Other peak ratios did not show strong pressure dependence as seen in the $(30 \overline{4}) /(203)$ ratio in Table 1 . This implies that during the reaction under high pressure of $50 \mathrm{MPa}$, the crystal grains favored the $b$-axis grain growth along the direction perpendicular to $P$. This was contrasting from the conventional methods using SPS for densification purpose only, in which no significant anisotropy was detected. It is possible that the pre-synthesized polycrystalline $\mathrm{W}_{18} \mathrm{O}_{49}$ powder is not easily re-oriented during the densification. Nevertheless, during reactive SPS and under high influence of uniaxial pressure, the growth of the $\mathrm{W}_{18} \mathrm{O}_{49}$ lattice under the formation reaction between the precursors would follow the minimum formation energy route, thus bringing about the highly preferential grain growth perpendicular to the applied pressure $P$.

Table 1. Pressures dependence of the relative peak intensity

\begin{tabular}{l|ll|ll}
\multicolumn{4}{|c}{ ratios for $(010) /(30 \overline{4})$ and $(30 \overline{4}) /(203)$} \\
\hline SPS & \multicolumn{2}{|c}{$(010) /(30 \overline{4})$ ratio } & \multicolumn{2}{c}{$(30 \overline{4}) /(203)$ ratio } \\
pressure & $P / /$ plane & $P \perp$ plane & $P / /$ plane & $P \perp$ plane \\
\hline $15 \mathrm{MPa}$ & 3.31 & 1.72 & 1.24 & 1.19 \\
\hline $30 \mathrm{MPa}$ & 3.47 & 1.54 & 1.26 & 1.21 \\
\hline $50 \mathrm{MPa}$ & 8.69 & 0.28 & 1.28 & 1.26 \\
\hline
\end{tabular}
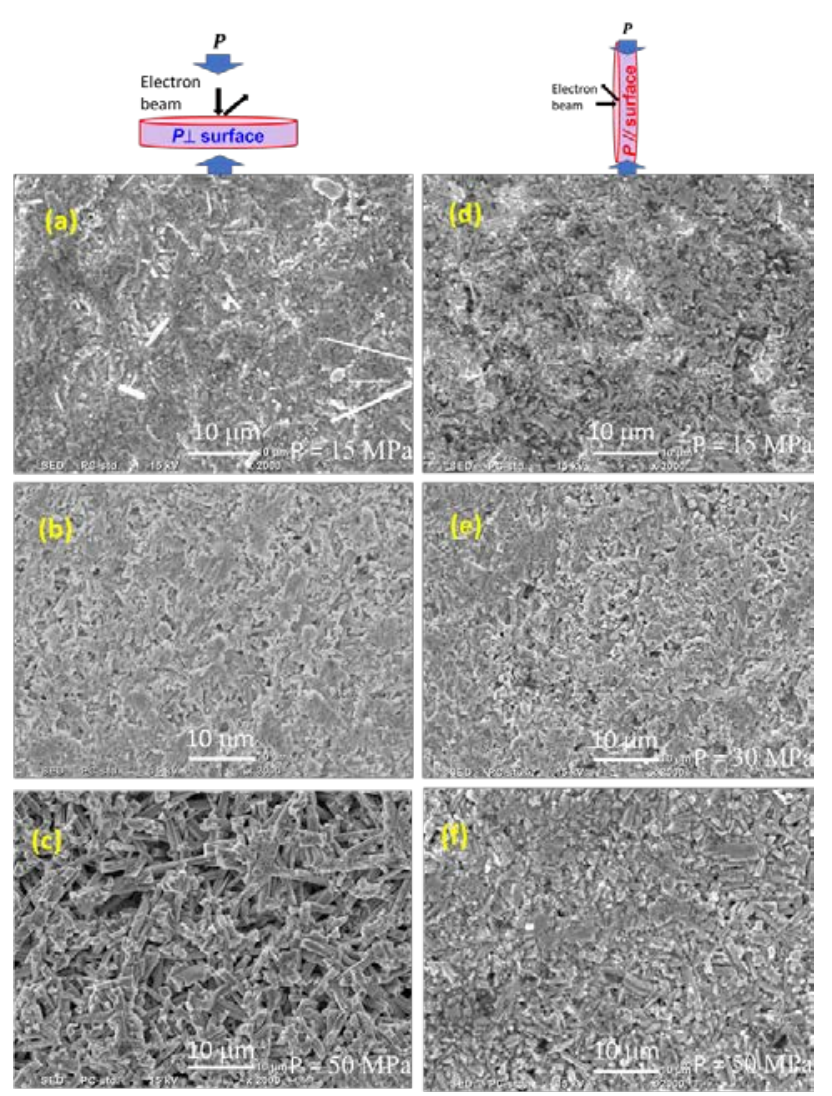

Figure 4. Scanning electron microscope images of $\mathrm{W}_{18} \mathrm{O}_{49}$ sample synthesized by direct SPS. Views of $P \perp$ fracture 
surfaces (a, b, c), and $P$ // fracture surfaces (e, d, f) of samples synthesized under different applied pressure of 15, 30 and 50 MPa, respectively.

Fig. 4 shows the SEM images of the $\mathrm{W}_{18} \mathrm{O}_{49}$ samples synthesized by direct SPS with views of fracture surfaces on the $P \perp$ plane (a, b, c), and those on the $P / /$ plane (e, d, $\mathrm{f}$ ), respectively, under different applied pressure of 15, 30 and $50 \mathrm{MPa}$. The sample synthesized under $15 \mathrm{MPa}$ was dense without visible crystallite or preferential grain orientation along either directions. Small needle-like crystallites were observed in the SEM images of sample synthesized under $30 \mathrm{MPa}$, implying a possibility of anisotropic thermoelectric properties due to the shape of the grains. However, no significant anisotropy of the grain orientation was observed in the images along either directions, and hence the anisotropy in the thermoelectric properties would be weak.
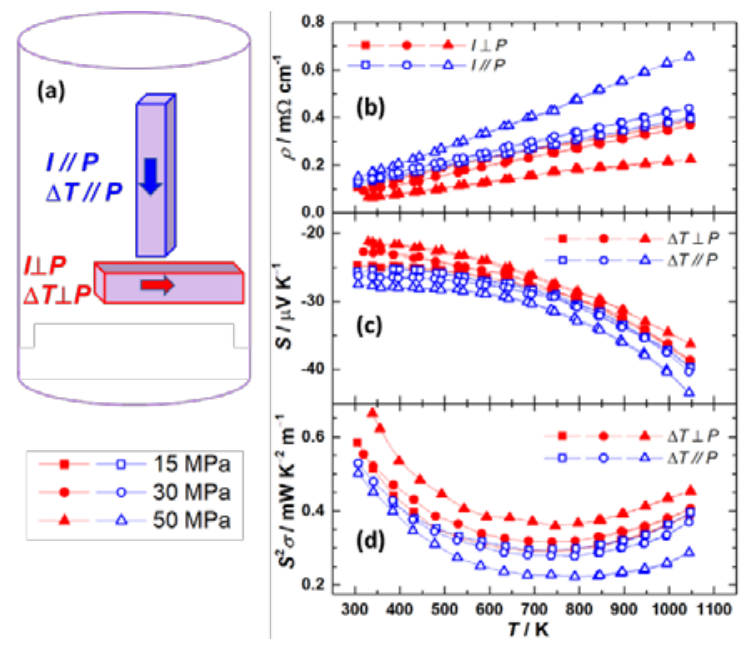

Figure 5. (a) $\rho$ and $S$ were measured from bar-shaped samples through an applied current $I$ and a temperature difference $\Delta T$. The measurement directions, parallel // and perpendicular $\perp$ to the applied pressure axis $P$, were denoted by the respective arrows. Temperature dependence of (b) the resistivity $\rho$, (c) the Seebeck coefficient $S$, (d) the power factor $S^{2} \rho^{-1}$ for samples with different SPS applied pressures (15, 30,

$50 \mathrm{MPa}$ ). Data measured for $P \perp$ and // directions are designated by closed and open symbols, respectively.

Nevertheless, for the sample synthesized under $50 \mathrm{MPa}$, many rod- and column-shaped crystallites lying on the fracture surface could be identified (Fig. 4 (c)). Those crystallites are of similar shapes to those of $\mathrm{W}_{18} \mathrm{O}_{49}$ nanowires and nano-rods ${ }^{5,31}$, which is elongated along the $b$-axis. While the crystallites are also visible in the fracture surface on the $P / /$ plane, there are distinct differences between the two directions regarding the elongation and orientation of the crystallites. The sample exhibited a strong anisotropic nature with the preferential grain growth along the $P \perp$ plane. We attempted to estimate the average diffraction domain dimensions by using the Scherrer equation ${ }^{32}$ ). The calculated crystallite sizes for (100) were $31.4 \mathrm{~nm}$ and $29.2 \mathrm{~nm}$, for (010) were $72.7 \mathrm{~nm}$ and $71.9 \mathrm{~nm}$, for (001) were $45.2 \mathrm{~nm}$ and $48.4 \mathrm{~nm}$, with respect to the observed $P \perp$ and $P / /$ planes, respectively. Thus, the sizes of the crystallites observed in the SEM images are much larger than that of the diffraction domains, indicating their polycrystalline characters.

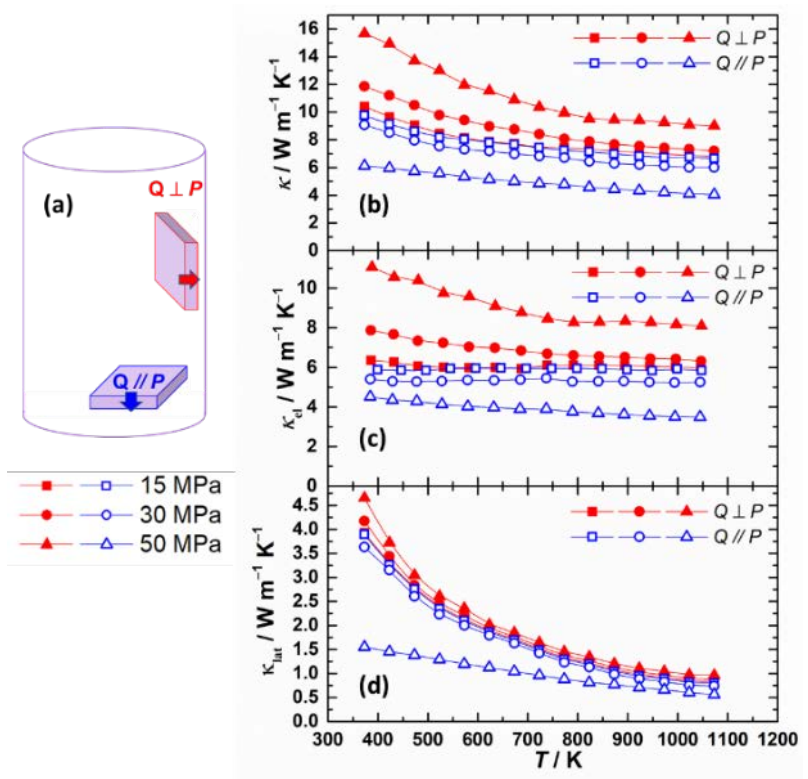

Figure 6. (a) $\kappa$ was measured from disc-shaped samples through a heat transfer $Q$ from laser pulses. The measurement directions, parallel // and perpendicular $\perp$ to the applied pressure $P$ axis, were denoted by the respective arrows.

Temperature dependence of (b) the total thermal conductivity $\kappa$ tot, (c) the electron thermal conductivity $\kappa_{\mathrm{e}}$, and (d) the lattice thermal conductivity $\kappa_{\text {lat }}$ for the samples with different SPS applied pressures (15, 30, $50 \mathrm{MPa}$ ). Data measured for $P \perp$ and

// directions are designated by closed and open symbols, respectively.

The temperature dependence of the electrical resistivity $\rho$, the Seebeck coefficient $S$, and the thermal conductivity $\kappa_{\text {tot }}$ are presented in Figs. 5 (b), (c), and Fig. 6 (b). To study the anisotropy in the transport properties, characterizations of the thermoelectric parameters were conducted in the corresponding directions, where $I, \Delta T$, and the thermal flux $Q$ are applied along the designated directions of $P \perp$ and $P / /$,respectively, as shown in the illustration in Fig. 5 (a) and Fig. 6 (a). Weakly anisotropic $\rho$ was observed in the sample synthesized under applied pressure of 15 and $30 \mathrm{MPa}$, with slightly larger $\rho$ values along the $P / /$ direction and somewhat smaller $\rho$ values along the $P \perp$ direction. The $\rho$ values of the samples are quite similar to the reported values of conventionally synthesized bulk $\mathrm{W}_{18} \mathrm{O}_{49}$, which showed metallic behavior with electrons as the dominant charge carriers ${ }^{17)}$. Nevertheless, a large anisotropy was observed for the sample synthesized under $50 \mathrm{MPa}$ uniaxial pressure, with a significant reduction in the $\rho$ value down to 0.06 $\mathrm{m} \Omega \mathrm{cm}^{-1}$ along the $P \perp$ direction, and an increase to 0.17 
$\mathrm{m} \Omega \mathrm{cm}^{-1}$ along the $P / /$ direction at $330 \mathrm{~K}$, showing about 3 times difference. The preferential grain growth would enhance the electron mobility along the $P \perp$ direction, while suppressing the electron transport in the $P / /$ direction. Accordingly, the $S$ values of the samples sintered under 15 and $30 \mathrm{MPa}$ are very near and comparable to the reported values of conventionally prepared $\mathrm{W}_{18} \mathrm{O}_{49}$, and hence so is the power factor $S^{2} \rho^{-1}$. As the same as the $\rho$ values, a distinct anisotropy was found in the $S$ values of the sample sintered under $50 \mathrm{MPa}$, where $|S|$ is larger along the $P / /$ direction but smaller along the $P \perp$ direction than the values shown by other samples. Consequently, the sample sintered under $50 \mathrm{MPa}$ attained the highest $S^{2} \rho^{-1}$ value of $0.5 \mathrm{~mW} \mathrm{~K}^{-2} \mathrm{~m}^{-1}$ and the lowest value of $0.28 \mathrm{~mW} \mathrm{~K}^{-2} \mathrm{~m}^{-1}$ along the $P \perp$ and $P / /$ directions, respectively.

The anisotropy of $\kappa_{\text {tot }}$ values (Fig. 6 (b)) was noteworthy; it was always higher along the $P / /$ direction, and lower along the $P \perp$ direction, compared to conventionally synthesized samples ${ }^{9}$ ). The increases and decreases became more significant with the applied pressure $P$. The highest and lowest $\kappa_{\text {tot }}$ values were both observed for the sample sintered under $50 \mathrm{MPa}$. Assuming the Wiedemann-Franz law for the electron thermal conductivity $\kappa_{\mathrm{el}}=L T \rho^{-1}$, the lattice thermal conductivity $\kappa_{\text {lat }}$ was estimated from the relation $\kappa=\kappa_{\text {lat }}+\kappa_{\text {el }}$. First, we attempted to use the constant Lorenz number $L=2.44$ $\times 10^{-8} \mathrm{~W} \Omega \mathrm{K}^{-2}$, according to the metallic behavior of the materials. However, at high temperature reaching $1073 \mathrm{~K}$, $\kappa_{\text {el }}$ became larger than the total $\kappa$, suggesting that the approximation was unreliable. Hence, a modified equation $L(T)=1.5+\exp (-|S| / 116)\left[10^{-8} \mathrm{~W} \Omega \mathrm{K}^{-2}\right]$ was used instead, in consideration of the correlation between $S$ and $L^{33}$ ). The temperature dependence of $\kappa_{\mathrm{el}}$ and $\kappa_{\text {lat }}$ are presented in Fig. 6 (c), (d). It was revealed that the major component of the high $\kappa$ values of the samples are mostly its electronic part $\kappa_{\mathrm{el}}$, and that actually $\kappa_{\text {lat }}$ of the oxide is impressively low. Very interestingly, the $\kappa_{\text {lat }}$ values of all the samples are closely matched each other regardless of the directions, except for that along the $P / /$ direction in the sample sintered under $50 \mathrm{MPa}$. The significantly lower $\kappa_{\text {lat }}$ values along the $P / /$ direction could be attributed to the phonon scattering effect by closely packed needle- or rodlike grains lying in the $P \perp$ plane (Fig. 4 (c)), offering much larger scattering probability for the phonons traveling along the $P / /$ direction, where the phonons must run across the needle-like grains in the radial direction, not in the longitudinal direction.

The weak anisotropic properties of the sample sintered under 15 and $30 \mathrm{MPa}$ resulted in quite similar dimensionless figure-of-merit ZT (presented in Fig. 7), with comparable behavior and magnitude to those reported for conventionally synthesized samples. Nonetheless, because of the largely anisotropic $\kappa$ values of the sample sintered under $50 \mathrm{MPa}$, the $Z T$ value of the sample was smallest along the $P \perp$ direction, despite the largest power factor values in this direction. On the other hand, being compensated by the considerably low $\kappa$ values, the $Z T$ value along the $P / /$ direction was enhanced to approximately 0.08 at $1073 \mathrm{~K}$. Since the synthesis conditions and the microstructures were not optimized yet, and ZT can be further boosted with higher anisotropy. The temperature dependence of $Z T$ is still uplifting at $1073 \mathrm{~K}$, suggesting the better performance at higher temperatures.

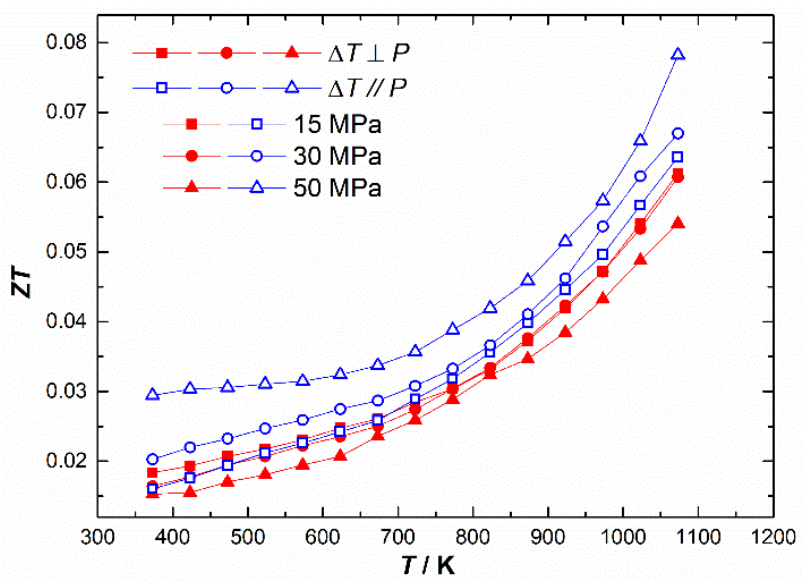

Figure 7. Temperature dependence of the dimensionless figure of merit for samples with different SPS applied pressures ( $P=15,30,50 \mathrm{MPa}$ ). Data measured for $P / /$ and $\perp$ directions are designated by closed and open symbols, respectively.

The thermoelectric properties of $\mathrm{W}_{18} \mathrm{O}_{49}$ are different from other conventional oxide materials such as $\mathrm{ZnO}$ based and $\mathrm{SnO}_{2}$-based oxides. While showing the n-type thermoelectric properties, pure $\mathrm{W}_{18} \mathrm{O}_{49}$ possesses very distinct metallic characters with the high electrical conductivity and small Seebeck coefficient strongly opposite to other oxides such as $\mathrm{ZnO}$ and $\mathrm{SnO}_{2}$. The high carrier concentration diminishes the power factor of $\mathrm{W}_{18} \mathrm{O}_{49}$ and significantly increases its thermal conductivity, resulting in very small and unappealing ZT values in comparison with other well-known oxide candidates. Nevertheless, the unique crystal structure of $\mathrm{W}_{18} \mathrm{O}_{49}$ largely contributes to its small lattice thermal conductivity, which is also opposite to many other conventional oxide materials. Consequently, improving thermoelectric performance of $\mathrm{W}_{18} \mathrm{O}_{49}$ requires a decrease in its carrier concentration, being in contrast to an increase for other oxide materials.

\section{Conclusions}

We have successfully synthesized single phase $\mathrm{W}_{18} \mathrm{O}_{49}$ directly from the starting materials of $\mathrm{WO}_{3}$ and $\mathrm{WO}_{2}$ via rapid reactive SPS, where the whole synthesis takes less than $2 \mathrm{~h}$ in total. This process is a significant improvement from conventional methods often involving complicated heating and cooling cycles in evacuated environments. In addition, the reaction between $\mathrm{WO}_{3}$ and $\mathrm{WO}_{2}$ to form tungsten suboxide $\mathrm{WO}_{3-x}(0<x \leq 1)$ could be more suitable than the reaction between $\mathrm{WO}_{3}$ and metal $\mathrm{W}$ 
powder, due to the similarities in the coordination environment of their $\mathrm{WO}_{6}$ octahedral building blocks.

Furthermore, anisotropic thermoelectric properties and influence of the applied pressure were revealed for the $\mathrm{W}_{18} \mathrm{O}_{49}$ samples synthesized by reactive SPS. The preferential orientation of the highly anisotropic grains under the high applied pressure resulted in an intrinsically low thermal conductivity samples despite its metallic nature. $Z T$ was enhanced to 0.08 at $1073 \mathrm{~K}$ for the sample sintered under a pressure of $50 \mathrm{MPa}$ in comparison with the ZT of 0.06 for the less oriented samples. Since the electronic properties of $\mathrm{W}_{18} \mathrm{O}_{49}$ is tunable to show semiconducting behavior, by combining the manipulatable $\kappa$ and anisotropy, this compound promises a new potential cost-effective $n$-type thermoelectric materials.

\section{Acknowledgments}

The authors would like to thank Dr. S. Hirata, Mr. W. Klich, Ms. S. Maneeyom, and Ms. B.T. Nguyen for their valuable discussion. This work was supported by JSPS KAKENHI Grant Number JP19H02800.

\section{References}

1) B.T. Prasetyo, Suyanto, M. Oktaufik, and S. Himawan, "Design, construction and preliminary test operation of bppt-3mw condensing turbine geothermal power plant,” Evergreen, 6 (2) 162-167 (2019). doi:10.5109/2321012.

2) R. Yoneda, "Research and technical trend in nuclear fusion in japan,” Evergreen, 4 (4) 16-23 (2017). doi:10.5109/1929677.

3) O.M.A.M. Ibrahim, and S. Yoshida, "Experimental and numerical studies of a horizontal axis wind turbine performance over a steep 2d hill," Evergreen, 5 (3) 12-21 (2018). doi:10.5109/1957496.

4) P. Pal, A.K. Nayak, and R. Dev, “A modified double slope basin type solar distiller: experimental and enviro-economic study," Evergreen, 5 (1) 52-61 (2018). doi:10.5109/1929730.

5) Y. Li, Y. Bando, and D. Golberg, "Quasi-aligned single-crystalline $\mathrm{W}_{18} \mathrm{O}_{49}$ nanotubes and nanowires,” Advanced Materials, 15 (15) 1294-1296 (2003). doi:10.1002/adma.200305122.

6) S. Shi, X. Xue, P. Feng, Y. Liu, H. Zhao, and T. Wang, "Low-temperature synthesis and electrical transport properties of $\mathrm{W}_{18} \mathrm{O}_{49}$ nanowires,” Journal of Crystal Growth, $310 \quad$ (2) 462-466 (2008). doi:10.1016/j.jcrysgro.2007.10.038.

7) W. Sahle, "Electron microscopy studies of $\mathrm{w}_{18} \mathrm{O} 49.1$. crystals formed by gaseous reduction of $\mathrm{WO}_{3}$," Journal of Solid State Chemistry, 45 (3) 324-333 (1982). doi:10.1016/0022-4596(82)90178-5.

8) W. Sahle, "Electron microscopy studies of $\mathrm{W}_{18} \mathrm{O}_{49} .2$. defects and disorder introduced by partial oxidation," Journal of Solid State Chemistry, 45 (3) 334-342 (1982). doi:10.1016/0022-4596(82)90179-7.

9) G. Kieslich, I. Veremchuk, I. Antonyshyn, W.G. Zeier,
C.S. Birkel, K. Weldert, C.P. Heinrich, E. Visnow, M. Panthöfer, U. Burkhardt, Y. Grin, and W. Tremel, "Using crystallographic shear to reduce lattice thermal conductivity: high temperature thermoelectric characterization of the spark plasma sintered magnéli phases $\mathrm{WO}_{2.90}$ and $\mathrm{WO}_{2.722}$," Physical Chemistry Chemical Physics, 15 (37) 15399 (2013). doi:10.1039/c3cp52361f.

10) B.-O. Marinder, "The pentagonal column and the reo $_{3}$-type structure," Angewandte Chemie International Edition in English, 25 (5) 431-442 (1986). doi:https://doi.org/10.1002/anie.198604311.

11) M. Ohtaki, and R. Hayashi, "Enhanced Thermoelectric Performance of Nanostructured $\mathrm{ZnO}$ : A possibility of selective phonon scattering and carrier energy filtering by nanovoid structure," in: 2006 25th International Conference on Thermoelectrics, 2006: pp. 276-279. doi:10.1109/ICT.2006.331368.

12) M. Ohtaki, "Recent aspects of oxide thermoelectric materials for power generation from mid-to-high temperature heat source," Journal of the Ceramic Society of Japan, 119 (1395) 770-775 (2011). doi:10.2109/jcersj2.119.770.

13) M. Ohtaki, and K. Araki, "Thermoelectric properties and thermopower enhancement of Al-doped $\mathrm{ZnO}$ with nanosized pore structure,” J. Ceram. Soc. Japan, 119 (1395) 813-816 (2011). doi:10.2109/jcersj2.119.813.

14) D.R. Clarke, "Materials selection guidelines for low thermal conductivity thermal barrier coatings," Surface and Coatings Technology, 163-164 67-74 (2003). doi:10.1016/S0257-8972(02)00593-5.

15) E.S. Toberer, A. Zevalkink, and G.J. Snyder, "Phonon engineering through crystal chemistry," J. Mater. Chem., $21 \quad$ (40) 15843-15852 (2011). doi:10.1039/C1JM11754H.

16) M.W. Gaultois, T.D. Sparks, C.K.H. Borg, R. Seshadri, W.D. Bonificio, and D.R. Clarke, "Datadriven review of thermoelectric materials: performance and resource considerations," Chem. Mater., $25 \quad$ (15) 2911-2920 (2013). doi:10.1021/cm400893e.

17) D.B. Migas, V.L. Shaposhnikov, and V.E. Borisenko, "Tungsten oxides. ii. the metallic nature of magnéli phases,” Journal of Applied Physics, 108 (9) 093714 (2010). doi:10.1063/1.3505689.

18) O. Guillon, J. Gonzalez-Julian, B. Dargatz, T. Kessel, G. Schierning, J. Räthel, and M. Herrmann, “FieldAssisted sintering technology/spark plasma sintering: mechanisms, materials, and technology developments,” Adv. Eng. Mater., 16 (7) 830-849 (2014). doi:10.1002/adem.201300409.

19) M. Tokita, "Recent and future progress on advanced ceramics sintering by spark plasma sintering," Nanotechnologies in Russia, 10 (3) 261-267 (2015). doi:10.1134/S1995078015020202. 
20) Z.A. Munir, U. Anselmi-Tamburini, and M. Ohyanagi, "The effect of electric field and pressure on the synthesis and consolidation of materials: a review of the spark plasma sintering method," Journal of Materials Science, 41 (3) 763-777 (2006). doi:10.1007/s10853-006-6555-2.

21) W.-T. Chiu, C.-L. Chen, and Y.-Y. Chen, “A strategy to optimize the thermoelectric performance in a spark plasma sintering process,” Scientific Reports, 6 (1) (2016). doi:10.1038/srep23143.

22) S. Hirata, and M. Ohtaki, "Simultaneous enhancement in the electrical conductivity and reduction in the lattice thermal conductivity leading to enhanced thermoelectric $\mathrm{ZT}$ realized by incorporation of metallic nanoparticles into oxide matrix,” Evergreen, 7 (1) 1-6 (2020). doi:10.5109/2740934.

23) L. Han, N. Van Nong, W. Zhang, L.T. Hung, T. Holgate, K. Tashiro, M. Ohtaki, N. Pryds, and S. Linderoth, "Effects of morphology on the thermoelectric properties of Al-doped $\mathrm{ZnO}$," RSC Advances, $4 \quad$ (24) $12353 \quad$ (2014). doi:10.1039/c3ra47617k.

24) L. Han, S.H. Spangsdorf, N.V. Nong, L.T. Hung, Y.B. Zhang, H.N. Pham, Y.Z. Chen, A. Roch, L. Stepien, and N. Pryds, "Effects of spark plasma sintering conditions on the anisotropic thermoelectric properties of bismuth antimony telluride,” RSC Adv., 6 (64) 59565-59573 (2016). doi:10.1039/C6RA06688G.

25) D.V. Dudina, and A.K. Mukherjee, "Reactive spark plasma sintering: successes and challenges of nanomaterial synthesis," Journal of Nanomaterials, 2013625218 (2013). doi:10.1155/2013/625218.

26) G. Franceschin, T. Gaudisson, N. Menguy, R. Valenzuela, F. Mazaleyrat, and S. Ammar, "On the limits of reactive-spark-plasma sintering to prepare magnetically enhanced nanostructured ceramics: the case of the $\mathrm{CoFe}_{2} \mathrm{O}_{4}-\mathrm{NiO}$ system," Scientific Reports, 9 (1) 14119 (2019). doi:10.1038/s41598-019-506574.

27) S.-K. Sun, G.-J. Zhang, W.-W. Wu, J.-X. Liu, J. Zou, T. Suzuki, and Y. Sakka, "Reactive spark plasma sintering of binderless wc ceramics at $1500^{\circ} \mathrm{c}$," International Journal of Refractory Metals and Hard Materials, $43 \quad 42-45 \quad$ (2014). doi:https://doi.org/10.1016/j.ijrmhm.2013.10.013.

28) A. Polaczek, M. Pekala, and Z. Obuszko, "Magnetic susceptibility and thermoelectric power of tungsten intermediary oxides,” Journal of Physics: Condensed Matter, 6 (39) 7909-7919 (1994). doi:10.1088/09538984/6/39/011.

29) F. Kaiser, P. Simon, U. Burkhardt, B. Kieback, Y. Grin, and I. Veremchuk, "Spark plasma sintering of tungsten oxides $\mathrm{WO}_{\mathrm{x}}(2.50 \leq \mathrm{x} \leq 3)$ : phase analysis and thermoelectric properties," Crystals, 7 (9) 271 (2017). doi:10.3390/cryst7090271.
30) J. Pfeifer, E. Badaljan, P. Tekula-Buxbaum, T. Kova'cs, O. Geszti, A.L. To'th, and H.-J. Lunk, "Growth and morphology of w18049 crystals produced by microwave decomposition of ammonium paratungstate," Journal of Crystal Growth, $169 \quad$ (4) 727-733 (1996). doi:10.1016/S0022-0248(96)00669-0.

31) S. Shi, X. Xue, P. Feng, Y. Liu, H. Zhao, and T. Wang, "Low-temperature synthesis and electrical transport properties of $\mathrm{W}_{18} \mathrm{O}_{49}$ nanowires," Journal of Crystal Growth, $\quad 310 \quad$ (2) 462-466 (2008). doi:10.1016/j.jcrysgro.2007.10.038.

32) A.L. Patterson, "The scherrer formula for $x$-ray particle size determination,” Phys. Rev., 56 (10) 978982 (1939). doi:10.1103/PhysRev.56.978.

33) H.-S. Kim, Z.M. Gibbs, Y. Tang, H. Wang, and G.J. Snyder, "Characterization of Lorenz number with Seebeck coefficient measurement,” 6 (2015). 